\title{
Patients' Preference and Experiences of Forced Medication and Seclusion
}

\author{
Irina Georgieva $\cdot$ C. L. Mulder • A. Wierdsma
}

Published online: 24 April 2011

(C) The Author(s) 2011. This article is published with open access at Springerlink.com

\begin{abstract}
This study examined patients' preferences for coercive methods and the extent to which patients' choices were determined by previous experience, demographic, clinical and intervention-setting variables. Before discharge from closed psychiatric units, 161 adult patients completed a questionnaire. The association between patients' preferences and the underlying variables was analyzed using logistic regression. We found that patients' preferences were mainly defined by earlier experiences: patients without coercive experiences or who had had experienced seclusion and forced medication, favoured forced medication. Those who had been secluded preferred seclusion in future emergencies, but only if they approved its duration. This suggests that seclusion, if it does not last too long, does not have to be abandoned from psychiatric practices. In an emergency, however, most patients prefer to be medicated. Our findings show that patients' preferences cannot guide the establishment of international uniform methods for managing violent behaviour. Therefore patients' individual choices should be considered.
\end{abstract}

Keywords Patients' preferences $\cdot$ Coercive measures $\cdot$ Seclusion $\cdot$ Forced medication

\section{Introduction}

Forced medication is the commonest method used on psychiatric wards to contain mentally ill patients who are violent toward themselves or others [1], while seclusion is the preferred measure in the Netherlands. These measures are controversial, because while they are intended to protect patients and those around them, they restrict freedom and are usually

I. Georgieva $(\bowtie) \cdot$ C. L. Mulder · A. Wierdsma

Department of Psychiatry, O3 Research Center O3, Erasmus MC,

P.O. Box 2040, 3000 CA Rotterdam, The Netherlands

e-mail: i.georgieva@erasmusmc.nl

I. Georgieva

Western Noord-Brabant Mental Health Center, Halsteren, The Netherlands

C. L. Mulder

BavoEuropoort, Rotterdam, The Netherlands 
applied against a patient's will. This causes serious ethical dilemmas for patients, their caregivers, clinicians and policymakers.

Forced medication is defined as the administration, with or without seclusion or restraint, of a rapid tranquilizer. By temporarily restricting the patient's freedom of movement, it is intended to control his or her behavior in a way that reduces the risk to their own safety or that of others [2]. Seclusion involves placing a service user in a locked room from which free exit is denied; it also involves isolation and the reduction of sensory stimuli [3].

Although professionals within and between countries have not found consensus on the best method of restricting patients [4], forced medication is the preferred method of dealing with emergencies in certain countries, such as Australia, the United Kingdom and the United States [5, 6]. Unlike their colleagues in these countries, Dutch psychiatric professionals use forced medication in only $22 \%$ of the situations when coercion is needed; instead, they prefer seclusion as the method of containment (59\%) [7].

The Dutch preference for seclusion is not supported by scientific evidence or legal regulations, because under the Netherlands' Mental Health Act, seclusion and forced medication are ranked equally for management of acute violence. Forced medication is used less often, due to a non-evidence based cultural norm that intramuscular administration of medication is a more serious violation of the integrity of an individual's body than being locked up in a seclusion room. This prejudice was probably partly the product of the Dutch legislation, which greatly restricts involuntary medication as part of planned involuntary treatment. However, as it has been shown that seclusion and forced medication are preferred by equal numbers of Dutch patients [8], this cultural norm is not necessarily shared by those who suffer its consequences.

This discrepancy between clinical practice and patients' preferences suggests that coercive practices in the Netherlands have more to do with institutional culture and traditions than with patient's preferences. Rather than seclusion, greater use of medication would fit better with what patients want-especially now Dutch mental health professionals and policymakers have increased their focus on the misapplication and overuse of seclusion $[9,10]$.

However, such a shift would be justified only if patients' preferences are consideredparticularly because there is no scientific evidences from controlled studies about the therapeutic value and the harmfulness of seclusion and forced medication [11], while qualitative studies have reported that seclusion and restraint have serious adverse effects [12-14].

This lack of evidence makes it difficult for psychiatric caregivers to decide which measure provides the most effective and least intrusive method of dealing with violent behaviour, whether under the terms of the Netherlands' Mental Health Act or of other legal systems. Better understanding of the underlying variables that influence patients' choices would therefore improve caregivers' decision-making. If account is taken of patients' own preferences, mental healthcare would become more patient-oriented, patient compliance and safety would be enhanced-possibly increasing not only the quality of treatment, but also patients' satisfaction.

To our knowledge, four studies to date have investigated patients' preferences regarding coercive measures $[3,8,15,16]$. The findings are contradictory. Veltkamp et al. reported that patients $(n=104)$ who had been secluded or involuntarily medicated or had undergone both measures judged these measures to be equally effective and aversive. The same authors found that more male patients expressed a preference for seclusion. 
Contrasting with these findings, another Dutch study [17] reported that patients $(n=88)$ who had previously been only secluded judged seclusion to be more aversive than forced medication, while patients who had no experience of coercion $(n=106)$ or had undergone both measures $(n=115)$ perceived both measures to be equally aversive.

Unlike the Dutch studies, the American study by Sheline and Nelson [18] found that the majority of the patients (64\%) preferred medication, while $24 \%$ preferred seclusion, and $10 \%$ preferred restraints. Earlier experiences of coercion in the sample were not mentioned. Finally, a strong preference towards medication was found also in the South African study conducted by Mayers et al. [3]. Fifty-seven percent of sedated patients agreed with the use of this measure, against only $25 \%$ of the secluded patients.

Although the findings of these studies are difficult to compare due to methodological differences, Dutch patients find seclusion to be a more acceptable intervention for dealing with emergencies. This is not surprising, seeing that seclusion is common practice in the Netherlands.

We therefore hypothesized that differences in patients' preferences reflect differences in coercive practices between countries, and, as Veltkamp et al. [8] have suggested, are strongly influenced by earlier coercive experiences. To test this hypothesis, we compared the preferences of patients who had not experienced coercion with those of patients who had either experienced seclusion alone or had experienced both seclusion and forced medication.

To date, even though patients who have not experienced coercion are in the majority, only one study [15] has explored their preferences. Neither are there many findings on how demographic and clinical variables are associated with patients' preferences. We therefore investigated which demographic and clinical variables (previous coercive experience, gender, legal status, age, diagnoses, perceived coercion, or global assessment of functioning) are most strongly associated with patients' preferences.

Although Vetkamp et al. [8] and Mayers et al. [3] found that patients appreciate an explanation of the reason coercive procedures have been used with them, none of the studies in question explored how other intervention-setting variables may influence patients' preferences - any of which might critically affect their preferences [19]. We therefore investigated whether the following factors had influenced patients' choice: (1) receiving or not receiving an explanation about the reason for being coerced, (2) perceived quality of care during the coercive measure, (3) experiencing or not experiencing improvement after the coercion, (4) approval of the coercive measure, (5) debriefing afterwards, and (6) subjective experience of the duration of the seclusion episodes.

In summary, our aim was to examine patients' experiences and preferences with regard to coercive measures, and the extent to which four factors-previous experiences of coercion, and demographic, clinical, and intervention-setting characteristics-are associated with patients' preferences.

\section{Methods}

\section{Setting}

In 2006, a project intended to reduce the use of seclusion and restraint was funded by a grant from the Dutch Ministry of Health and the Western Noord-Brabant Mental Health Center, where the study took place. The first step to achieving this objective was to obtain information about patients' experiences with coercive measures, and their preferences with 
regard to them. We therefore developed a questionnaire, which was then administered before discharge to individual patients in various closed psychiatric wards.

Participation in this study was completely voluntary. Because data were collected prospectively as part of a quality-control procedure approved by the institution's Board of Directors, approval by the medical ethical committee was not needed.

Instruments

As no suitable instrument existed, we developed a questionnaire in collaboration with representatives of the local patients' advocacy and family-support organization. It consisted of 31 questions focusing on (1) patients' experiences with forced medication and seclusion during their current period of hospitalization, and (2) the method of containment they would prefer in a future emergency, and also (3) perceived coercion, measured by a slightly adapted version of the Perceived Coercion Scale (PCS; MacArthur Perceived Coercion Scale; [20]). This is a 15-item scale consisting of three construct domains: (1) admission process; (2) inpatient treatment; and (3) medication management. Five statements are addressed per domain (e.g. 'It was my decision to cooperate with the treatment/ supervision.'), which are answered on a 5-point Likert-type scale ranging from 1 (full agreement) to 5 (full disagreement). Scores range from 15 to 75 , with higher scores indicating higher levels of perceived coercion.

Forced medication was defined as "administration of oral or intramuscular medication against the patient's will during emergencies, which is not part of the regular treatment".

The initial version (Version A) of the questionnaire was intended to investigate the methods of containment preferred solely by patients who had been contained during their stay. In January 2008, the questionnaire was changed slightly so as to allow us also to investigate patients' preferences who had had no experience of containment (Version B).

Data on diagnoses according to DSM-IV [APA 1987] and Global Assessment of Functioning (GAF), were retrospectively collected from patients' clinical files. GAF is widely used in clinical practice to assess the level of patient functioning. Scores range from 0 to 100 , with higher scores indicating better daily functioning and milder symptoms.

Patients

From the beginning of 2007 until the end of 2009, 451 patients were asked to complete the questionnaire. This generated 376 responses (83\%). From this sample, we selected only respondents who completed the questionnaire before discharge of their first admission and answered the question "If you could choose between seclusion or forced medication, what would be your choice?". Until January 2008, 82 patients met these inclusion criteria and completed version A of the questionnaire, followed by 79 patients who completed version B. In total, 161 respondents were included in this study.

\section{Statistical Analyses}

Chi square analyses and Anova $\mathrm{F}$ tests were used to compare patients with different coercive experience on the following variables: (1) preferences for coercive measures (2) sociodeomographic variables; (3) clinical variables; and (4) intervention-setting variables.

Preference for seclusion or forced medication was explored using unadjusted (crude) odds ratios with corresponding $95 \%$ confidence intervals (CI) for all predictors. Logistic 
regression analyses were performed using stepwise forward and backward procedures with 0.25 and 0.05 alpha levels of entry and removal respectively. Interaction effects and collinearities were checked for all main factors. Model selection was based on likelihood ratio test statistics. The fit of final models was assessed using Nagelkerke R2 and Model Chi-square. Data analyses were performed using SPSS 15.0.

\section{Results}

\section{Sample Characteristics}

First, the 161 respondents included in this study were compared with the remaining 215 respondents from the complete sample with regard to the following variables: age, gender, legal status upon admission, psychiatric diagnoses, GAF score and perceived coercion. There were no significant differences between the groups. The demographic, clinical and intervention-setting variables of these 161 respondents are presented in Table 1, where they are divided into three groups: "no experience of coercion" $(n=64)$, "experience of seclusion and forced medication" $(N=39)$ and "experience of seclusion only" $(N=58)$. Only four respondents had experienced forced medication without seclusion. Because of the small size of this subgroup, their answers were analysed together with data of patients who had been medicated and secluded.

Because some of the clinical files were incomplete and some of the respondents did not feel comfortable answering all of the questions, the $n$ and the percentage of respondents vary across the variables, as presented in Table 1.

Male patients and involuntary admitted patients had been subjected to coercive measures more often than others. Coerced patients scored significantly higher on the perceived coercion scale. Many of the patients had comorbid diagnoses (56\%), 40 had a psychotic disorder, 44 a mood disorder, 36 a personality disorder, 43 an addiction disorder, and 11 post-traumatic stress disorder (PTSD). Patients with psychotic disorder were more often secluded. We therefore used this diagnostic criterion (psychotic disorder: yes or no) to dichotomize the data for further analyses.

There were no significant differences between the three groups for age and GAF scores.

\section{Experiences and Preferences for Forced Medication or Seclusion}

Forced medication during emergencies was preferred by $57 \%$ of the patients, which consisted of those who had not experienced coercion (70\%), those who had undergone both measures (62\%) and those who had undergone seclusion alone (40\%). The last group patients were significantly more satisfied with the duration of seclusion episodes and the improvement after the intervention than the respondents who had undergone both measures, which may explain their stronger preference for seclusion.

The reasons for the use of the restrictive measure had been explained to most but not all of the patients in question (83\%), most of whom were also satisfied with the quality of care they had received and with their contact with the staff during the coercive intervention (72\%). Most had been debriefed after the intervention (67\%), and most retrospectively approved the measure (69\%).

As Table 1 shows, there were no significant differences between the groups on these intervention-setting variables. 


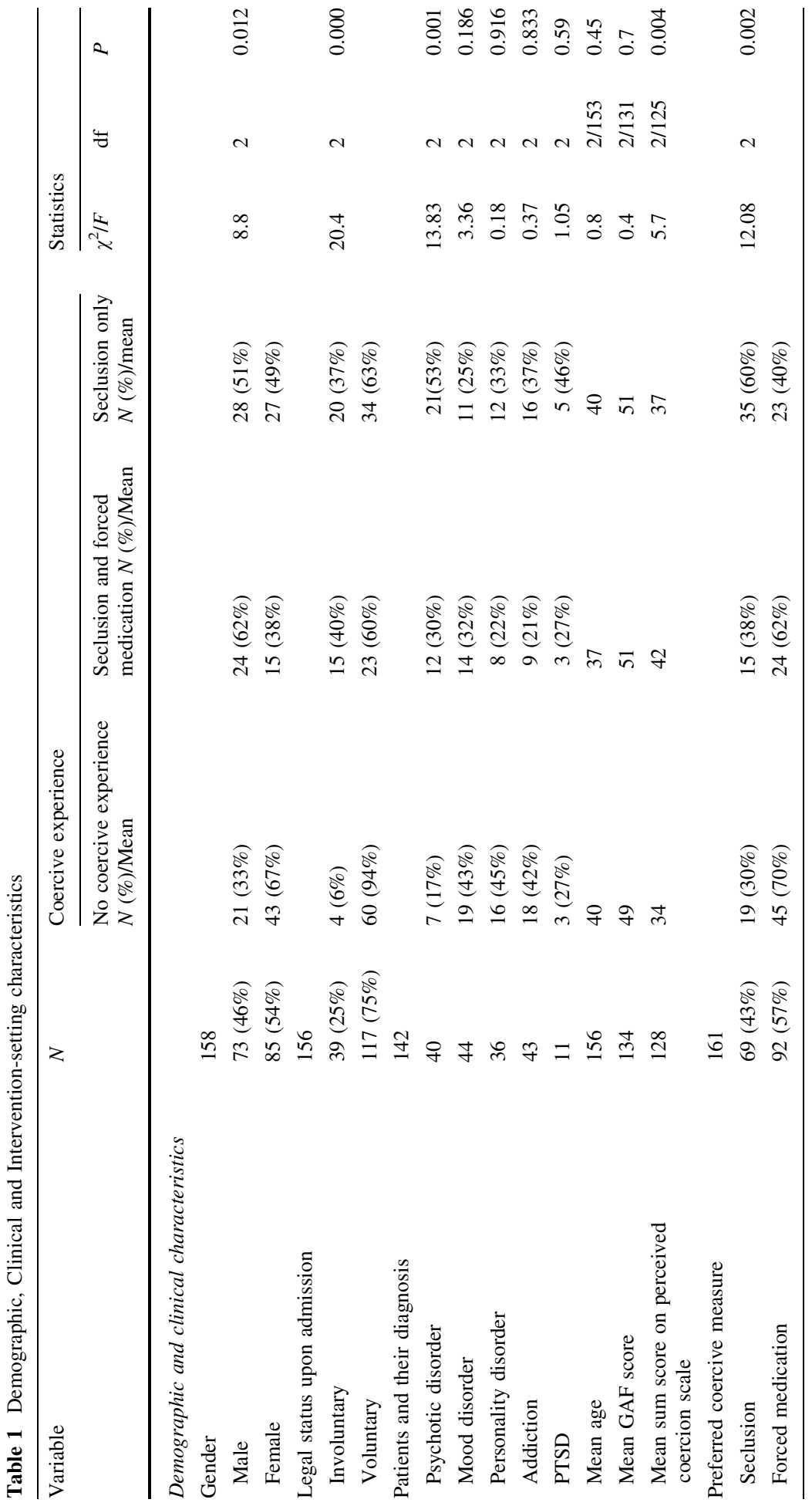




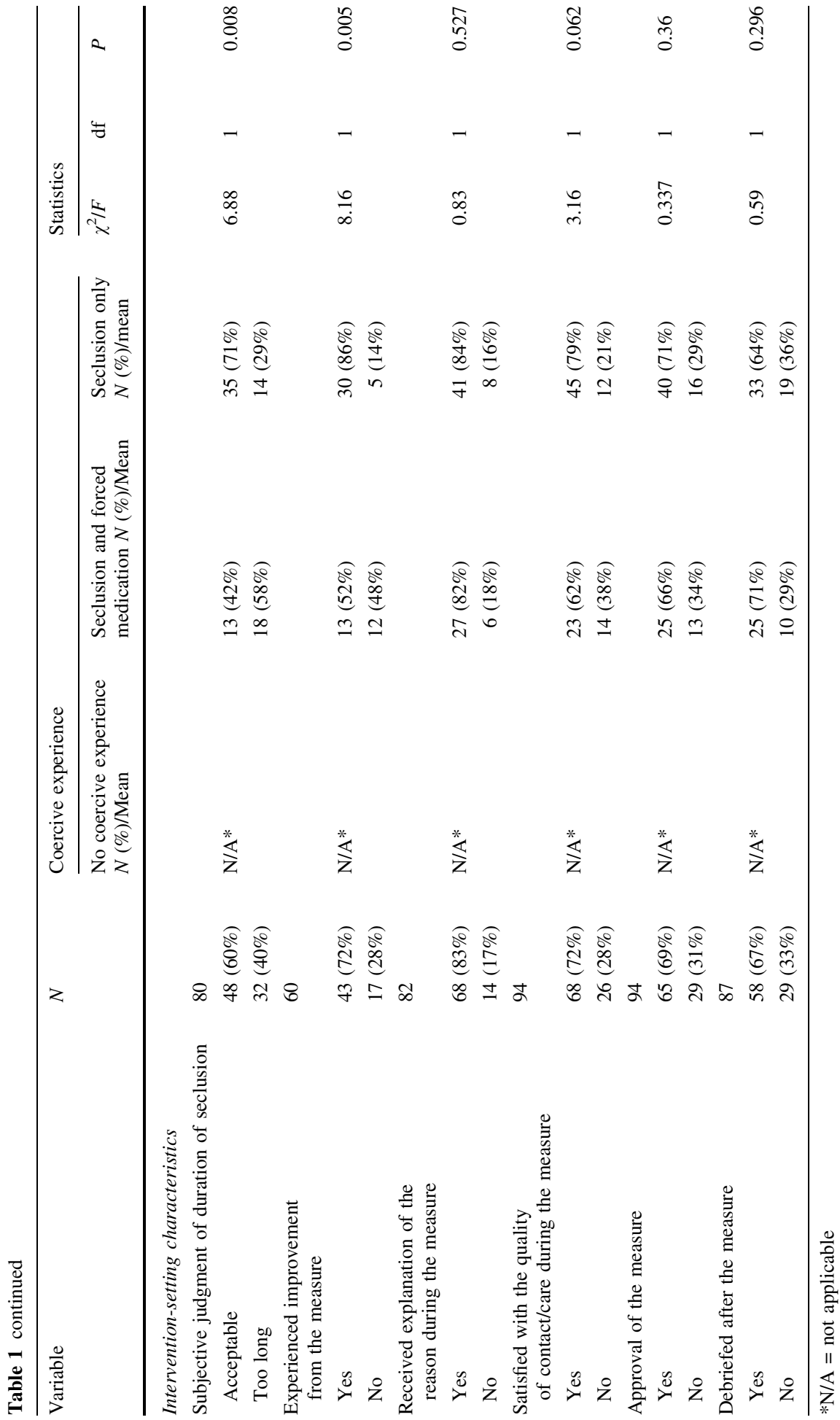


Table 2 Bivariate associations between demographic and clinical variables with patients' preferences for patients with or without coercive experience $(N=161)$

$* P<0.25$; ** $P<0.05$;

*** $P<0.01$; coding: seclusion

(0), forced medication (1)

\begin{tabular}{llll}
\hline Predictor & \multicolumn{2}{l}{$\begin{array}{l}\text { Preference for forced } \\
\text { medication }\end{array}$} \\
\cline { 2 - 4 } & $N$ & OR & $95 \%$ CI \\
\hline No experience of coercive measures & & 3.6 & $1.7-7.6^{* * * *}$ \\
Experience of seclusion or & 161 & 2.4 & $1.06-5.6^{* *}$ \\
$\quad$ forced medication & & & \\
Experience of seclusion & & 1.0 & Reference \\
Male gender & 158 & 1.0 & $0.5-1.9$ \\
Voluntary legal status & 156 & 2.8 & $1.3-5.8^{* * *}$ \\
Diagnosed with psychotic disorder & 142 & 0.9 & $0.4-1.9$ \\
Age & 156 & 0.9 & $0.9-1.0$ \\
GAF score $>50$ & 134 & 0.9 & $0.5-1.8$ \\
GAF score $<50$ & & & Reference \\
Perceived coercion score & 128 & 0.9 & $0.9-1.0^{* *}$ \\
\hline
\end{tabular}

\section{Association of Demographic and Clinical Variables With Patients' Preferences}

Table 2 presents the odds ratios and the confidence intervals for demographic and clinical variables and patients' preferences for forced medication as opposed to seclusion for all 161 respondents. Three variables were entered into the multivariate logistic regression: (1) experience or no experience of coercive measures, (2) legal status and (3) perceived coercion. The final logistic regression model consisted of two main associations: no experience of coercion (odds ratio $[\mathrm{OR}]=3$; 95 percent confidence interval $[C I]=1.3-6.6)$; previous experience with seclusion and forced medication $(\mathrm{OR}=2.5$; $\mathrm{CI}=1-6)$; and voluntary admission $(\mathrm{OR}=2.2 ; \mathrm{CI}=0.97-4.9)$; Nagelkerke $R^{2}=0.13$ and Model Chi-square $=4.8, \mathrm{df}=3, P=0.186$.

Association of Demographic, Clinical and Intervention Setting Variables With Patients' Preferences

Table 3 presents the odds ratios and the confidence intervals for demographic, clinical, intervention-setting variables, and patients' preferences for forced medication as opposed to seclusion, only for the 97 respondents who had experience with coercive measure(s). Six variables were entered into the multivariate logistic regression: (1) the type of coercive experience, (2) legal status, (3) subjective judgment of the duration of seclusion, (4) explanation of the reason for the use of the restrictive measure, (5) satisfaction with the quality of care received, and (6) approval of the measure. The final logistic regression model consisted of two main associations: discontentment with the duration of seclusion $(\mathrm{OR}=5 ; \mathrm{CI}=2-15)$, and voluntary admission status $(\mathrm{OR}=2 ; \mathrm{CI}=0.8-7)$; Nagelkerke $R^{2}=0.24$ and Model Chi-square $=4.9, \mathrm{df}=2, P=0.087$.

\section{Discussion}

We found that the majority of our respondents $(57 \%)$ stated that they would prefer to be medicated in a future emergency. Their preferences were affected by their previous 
Table 3 Bivariate associations of demographic, clinical and intervention-setting variables with preference for coercive measure for patients with coercive experience $(N=97)$

\begin{tabular}{llll}
\hline Predictor & \multicolumn{3}{l}{ Preference for forced medication } \\
\cline { 2 - 5 } & $N$ & OR & $95 \%$ CI \\
\hline Experience of seclusion & 97 & 0.4 & $0.2-0.94^{* *}$ \\
Male gender & 94 & 1.6 & $0.7-3.5$ \\
Voluntary legal status & 92 & 3.0 & $1.2-7.3^{* *}$ \\
Diagnosed with psychotic disorder & 83 & 0.9 & $0.4-2.4$ \\
Age & 93 & 0.9 & $0.9-1.0$ \\
GAF score $>50$ & 78 & 1.2 & $0.5-3.0$ \\
GAF score $<50$ & & & Reference \\
Perceived coercion score & 65 & 0.9 & $0.9-1.0$ \\
Duration of seclusion perceived as too long & 80 & 5.3 & $2.0-14.0^{* * *}$ \\
Experienced improvement after the measure & 60 & 1.1 & $0.3-3.5$ \\
Received explanation of the reason for the measure & 82 & 2.0 & $0.6-6.7^{*}$ \\
Satisfied with the quality of contact/care during the measure & 94 & 2.3 & $0.9-5.8^{*}$ \\
Approval of the measure & 94 & 2.7 & $1.0-6.6^{* *}$ \\
Debriefed after the measure & 87 & 1.3 & $0.5-3.2$ \\
\hline
\end{tabular}

$* P<0.25$;* $P<0.05 ; * * * P<0.01 ;$ coding: seclusion (0), forced medication (1)

experiences of coercion: compared to patients who had only been secluded, those who had no experience of coercion were three times more likely to choose forced medication, and those who had experienced both measures were 2.5 times more likely. Those who had been secluded were more likely to choose seclusion if they were content with the duration of the seclusion episode; if they perceived this to be too long, they were 5 times more likely to find forced medication to be more appropriate. Voluntarily admitted patients were two times more likely to favor medication than those who had been admitted involuntarily.

These results confirmed our hypothesis that preferences for coercive measure are influenced by earlier experiences. This could explain why Dutch patients tend to favour seclusion more than patients from countries where violent behaviour is suppressed mainly by forced medication. This makes it difficult to compare findings on patients' preferences, and also to guide the establishment of uniform criteria for coercive practices across countries.

Stolker et al. [21] found a significant association between lack of privacy and a more positive view of seclusion. The high approval of seclusion shown in our results $(71 \%)$ may therefore be partly explained by patients' residence in multiple-bed psychiatric wards. However, because most secluded patients $(86 \%)$ experienced an improvement, we conclude that seclusion should not necessarily be excluded from the repertoire of coercive practises-provided the patient is mobilized as soon as the acute danger has passed. This is because the duration of seclusion seems to be a critical factor in patients' choices.

In this connection, there is evidence that the duration of seclusion episodes can be reduced by structural risk-assessment [22]. A significant reduction $(>40 \%)$ in the duration of seclusion and restraint can also be achieved by legal regulations [23, 24], such as the socalled "one-hour-rule", which stipulates that physicians or registered nurses must, within 
one hour of such measures being instituted, conduct face-to-face assessment of all individuals placed in seclusion or restraint [25].

Our findings confirm the controversial nature of coercive measures. Patients who had undergone a coercive intervention during hospitalization judged their treatment to be more coercive than those who had not. On the other hand, a surprisingly high percentage of them experienced an improvement (72\%), and also approved the coercive measure(s) (69\%)though this contrasts with earlier studies, which showed that only $4 \%$ of secluded patients considered the intervention to be beneficial [26], and that only $29 \%$ approved the coercive measures [27].

According to the theory of cognitive dissonance [28], when people hold two contradictory ideas simultaneously, they tend to reduce the resulting discomfort by justifying or rationalizing their attitudes and beliefs. In our case, patients may have been angry and dissatisfied because of their containment, but also have felt guilty due to their violent behaviour, or have felt fear due to their dependence on hospital staff. These contradictory feelings may have led them to justify their beliefs and attitudes; by inflating their approval of coercive practices and reinforcing their denial of any negative consequences, they may thus have become less critical of them.

In accordance with the cognitive dissonance theory, Kleber and Brom [29] found that human beings tend retrospectively to justify traumatic events so as to aid their acceptance of them. Patients should therefore be trained to think more critically and to become aware of their preferences; they should also be encouraged to reflect on their experiences [3]. They should also be educated about their rights with regard to the use of coercive measures.

Eighty-three percent of our respondents had been informed about the reason for their containment. As patients report the most negative experiences with seclusion when they do not understand it and when they have no options for discussing it with others [13], improvement was needed in $17 \%$ of cases.

Because respondents in this study were not always satisfied with the quality of care they had received, or with their contact with staff, clinical staff should openly discuss measures for improvement with patients. If staff provide enough psychological and informational support to patients during coercive events, the type of coercive measure may become less relevant.

Further, only $67 \%$ of our respondents were debriefed after the measure. To minimize emotional impact, debriefing should always take place [30]: as Scanlan [31] reports, it can successfully eliminate future seclusion and restraint. During debriefing, the most appropriate approach to prevent future crises should be discussed. These should be included in a relapse-prevention plan, or the least restrictive of the preferred interventions should be taken into account in psychiatric advance directives (PADs).

\section{Study Limitations}

Although this study gave us new insights into patients' preferences, and particularly into the variables that underlie them, our results reflect a coercive aspect of Dutch psychiatric healthcare that is characterised by many and long seclusion episodes [4], and which makes our results less generalizable to other countries.

As forced medication is rarely practised in the Netherlands, some respondents may also have had some difficulty in understanding its definition. This may have led to some underreporting. We did not specify whether forced medication involved the administration of benzodiazepines, antipsychotics or both, or whether it was combined with physical 
restraint, mechanical restraint or seclusion. As these are very different options, they might influence patients' preferences.

We should also acknowledge that we do not know the clinical and demographic characteristics of the patients who did not respond to the questionnaire (17\%). We are therefore unsure of the extent to which these patients are comparable with our respondents, and whether our findings are fully representative for inpatient psychiatric care.

As possible predictors of patient's preferences, data were collected on demographic and clinical variables, and on patients' subjective experiences. Even though this is the most extensive study to date, we realize that differences in patients' preferences may be attributable to underlying mechanisms that have not been considered here.

Similarly, future research might pay greater attention to the type and seriousness of aggression, the reason for seclusion or restraint, and the objective duration of seclusion episodes. Finally, we should add that the scope of our study was limited to the coercive measures that are used most often in the Netherlands, and that we did not investigate patients' preferences toward other freedom-restrictive interventions such as mechanical and physical restraints, continuous observation, or time-out.

\section{Recommendations}

As long as coercive measures are still clinical practice, and we want to practise evidence based medicine, while no objective scientific evidence from controlled studies can guide us into choosing the least restrictive and the most effective measure, the only rational way to choose the correct intervention is to consider patients' individual choices. This approach is strongly recommended by the Council of Europe, which states that people with mental illness have a right to individualized treatment, which should be discussed with the patient, reviewed and revised regularly and provided by properly qualified staff [32].

Legally, consideration of the patients' choice is not required. It is also difficult in situations where healthcare consumers are unknown to the services but violent on admission. In such emergency situations, psychiatric patients are judged not to be competent to take decisions on their treatment. As Van Citters et al. [33] have pointed out, this situation might be improved by the use of psychiatric advance directives (PADs), which are legal instruments that make it possible to document patient's preference regarding future mental health treatments, including coercive measures. It concerns a process of shared decision making, described earlier [34]. Such a document can also designate a surrogate decisionmaker for situations in which the patient loses the ability to make reliable treatment decisions during an acute episode of psychiatric illness [35].

Although, unfortunately, PADs are still rarely used and little evidence is available about their efficacy [36], Henderson et al. [37] showed that patients with advance directives focused on crisis prevention, were less likely to commit acts of violence and thus undergo compulsory treatment. Another study [38] also showed that due to PADs, patients' working alliance with clinicians improved significantly. Not only have numerous studies already confirmed that it is feasible to ask patients about their preferences regarding coercive measures [39, 40], other studies have shown that patients' involvement in treatment decisions leads to better treatment outcomes [41, 42].

Acknowledgments We would like to thank the Dutch Ministry of Health and Mental Health Centre Western North-Brabant for disbursing a grant for this project. We thank also Judith van Veldhoven for her help in organizing the collection of data, and Lyda Schuttert, Bart Willemse, Patrick van Haren, Ad Godschalk, Wim Mannie, Leonie Verhulst and Yvonne van der Beek for collecting it. 
Open Access This article is distributed under the terms of the Creative Commons Attribution Noncommercial License which permits any noncommercial use, distribution, and reproduction in any medium, provided the original author(s) and source are credited.

\section{References}

1. Raboch J, Kalisova L, Nawka A, et al.: Use of coercive measures during involuntary hospitalization: findings from ten European countries. Psychiatric Services 61(10):1012-1017, 2010.

2. Ashcraft L, Anthony W: Eliminating seclusion and restraint in recovery-oriented crisis services. Psychiatric Services 59(10):1198-1202, 2008.

3. Mayers P, Keet N, Winkler G, et al.: Mental health service users' perceptions and experiences of sedation, seclusion and restraint. International Journal of Social Psychiatry 56(1):60-73, 2010.

4. Steinert T, Lepping P: Legal provisions and practice in the management of violent patients. A case vignette study in 16 European countries. European Psychiatry 24(2):135-141, 2009.

5. Currier GW: The controversy over "chemical restraint" in acute care psychiatry. Journal of Psychiatric Practice 9(1):59-70, 2003.

6. Vorselman A: Seclusion, fixation and medication: the application of coercive measures in adult psychiatry internationally compared. In: Public Administration and Public Policy-European Studies. University of Twente, The Nertherlands, 2003.

7. Dutch Mental Health Inspectorate: Report Dutch Mental Health Inspectorate. Den Haag, 2008.

8. Veltkamp E, Nijman H, Stolker JJ, et al.: Patients' preferences for seclusion or forced medication in acute psychiatric emergency in the Netherlands. Psychiatric Services 59(2):209-211, 2008.

9. GGZ Nederland: 'Van beheersen naar voorkomen' stand van zaken rond het verminderen van separaties in de GGZ in Nederland. In: Gezondheid FP (Ed), 2008.

10. Tilburg Wv, van Veldhuizen JR, Beijaert EW, van de Ven-Dijkman MV, Mulder CL, Schulte PFJ, Sikkens EPK, Tholen AJ: Richtlijn besluitvorming dwang: opname en behandeling. In: NVvP-commissie Richtlijn besluitvorming dwang. Utrecht, 2008.

11. Sailas E, Fenton M: Seclusion and restraint for people with serious mental illnesses. Cochrane Database of Systematic Reviews (2):CD001163, 2000.

12. Nelstrop L, Chandler-Oatts J, Bingley W, et al.: A systematic review of the safety and effectiveness of restraint and seclusion as interventions for the short-term management of violence in adult psychiatric inpatient settings and emergency departments. Worldviews on Evidence-Based Nursing 3(1):8-18, 2006.

13. Hoekstra T, Lendemeijer HH, Jansen MG: Seclusion: the inside story. Journal of Psychiatric and Mental Health Nursing11(3):276-283, 2004.

14. Moran A, Cocoman A, Scott PA, et al.: Restraint and seclusion: a distressing treatment option? Journal of Psychiatric and Mental Health Nursing 16(7):599-605, 2009.

15. Welles F, Widderschoven TP: Separatie of medicatie: de patient aan het woord. Maandblad Geestelijke volksgezondheid 62(6):475-486, 2007.

16. Sheline Y, Nelson T: Patient choice: deciding between psychotropic medication and physical restraints in an emergency. Bulletin of the American Academy of Psychiatry and the Law 21(3):321-329, 1993.

17. Welles F, Widderschoven TP: Separatie of medicatie: de patient aan het woord. Maandblad Geestelijke volksgezondheid 62:475-486, 2007.

18. Coburn VA, Mycyk MB: Physical and chemical restraints. Emergency Medicine Clinics of North America 27(4):655-667, ix, 2009.

19. Bernstein R: Commentary: commentary on the "choice" between seclusion and forced medication. Psychiatric Services 59(2):212, 2008.

20. Gardner W, Hoge SK, Bennett N, et al.: Two scales for measuring patients' perceptions for coercion during mental hospital admission. Behavioral Sciences and the Law 11(3):307-321, 1993.

21. Stolker JJ, Nijman HL, Zwanikken PH: Are patients' views on seclusion associated with lack of privacy in the ward? Archives of Psychiatric Nursing 20(6):282-287, 2006.

22. van de Sande R, Hellendoorn, E, Roosenschoon B, Noorthoorn E, Nijman H, van der Staak C, Mulder CL: De CrisisMonitor. Het signaleren van agressie en het voorkomen van separatie. Maandblad Geestelijke volksgezondheid 64(6):540-550, 2009.

23. LeBel J: Regulatory change: a pathway to eliminating seclusion and restraint or "regulatory scotoma"? Psychiatric Services 59(2):194-196, 2008.

24. Currier GW, Farley-Toombs C: Datapoints: use of restraint before and after implementation of the new HCFA rules. Psychiatric Services 53(2):138, 2002. 
25. Martin A, Fawcett B, Lee T: Seclusion and restraint "one-hour rule". Journal of the American Academy of Child and Adolescent Psychiatry 43(11):1322-1324, 2004.

26. Meehan T, Bergen H, Fjeldsoe K: Staff and patient perceptions of seclusion: has anything changed? Journal of Advanced Nursing 47(1):33-38, 2004.

27. Eriksson KI, Westrin CG: Coercive measures in psychiatric care. Reports and reactions of patients and other people involved. Acta Psychiatrica Scandinavica 92(3):225-230, 1995.

28. Festinger L: A Theory of Cognitive Dissonance. Stanford University Press, Stanford, CA, 1957.

29. Dickinson T, Ramsdale S, Speight G: Managing aggression and violence using rapid tranquillisation. Nursing Standard 24(7):40-49; quiz 50, 52, 2009.

30. Huckshorn KA: Re-designing state mental health policy to prevent the use of seclusion and restraint. Administration and Policy In Mental Health 33(4):482-491, 2006.

31. Scanlan JN: Interventions to reduce the use of seclusion and restraint in inpatient psychiatric settings: what we know so far. A review of the literature. International Journal of Social Psychiatry 56(4): 412-423, 2009.

32. Kingdon D, Jones R, Lonnqvist J: Protecting the human rights of people with mental disorder: new recommendations emerging from the Council of Europe. British Journal of Psychiatry 185:277-279, 2004.

33. Van Citters AD, Naidoo U, Foti ME: Using a hypothetical scenario to inform psychiatric advance directives. Psychiatric Services 58(11):1467-1471, 2007.

34. Liegeois A, Eneman M: Ethics of deliberation, consent and coercion in psychiatry. Journal of Medical Ethics 34(2):73-76, 2008.

35. Srebnik D, Russo J: Use of Psychiatric Advance Directives During Psychiatric Crisis Events. Administration and Policy in Mental Health, 2008.

36. Campbell LA, Kisely SR: Advance treatment directives for people with severe mental illness. Cochrane Database of Systematic Reviews (1):CD005963, 2009.

37. Allen MH, Currier GW: Use of restraints and pharmacotherapy in academic psychiatric emergency services. General Hospital Psychiatry 26(1):42-49, 2004.

38. Swanson JW, Swartz MS, Elbogen EB, et al.: Facilitated psychiatric advance directives: a randomized trial of an intervention to foster advance treatment planning among persons with severe mental illness. American Journal of Psychiatry 163(11):1943-1951, 2006.

39. Srebnik DS, Russo J, Sage J, et al.: Interest in psychiatric advance directives among high users of crisis services and hospitalization. Psychiatric Services 54(7):981-986, 2003.

40. Amering M, Stastny P, Hopper K: Psychiatric advance directives: qualitative study of informed deliberations by mental health service users. British Journal of Psychiatry 186:247-252, 2005.

41. Harris M, Bergman HC: Differential treatment planning for young adult chronic patients. Hospital and Community Psychiatry 38(6):638-643, 1987.

42. Harden J, Hales RE, Amen D, et al.: Inpatient participation in treatment planning: a preliminary report. General Hospital Psychiatry 8(4):287-290, 1986.

\section{Author Biographies}

Irina Georgieva, MSc is a psychologist and $\mathrm{PhD}$ candidate at Erasmus MC, Department of Psychiatry. Her research and recent publications are focused on evaluation of interventions for reducing the use of seclusion and restraint.

C. L. Mulder, MD, PhD is a psychiatrist and professor of Public Mental Health. He is a program leader of the Research Centre O3 at Erasmus University Medical Centre, Department of Psychiatry, psychiatrist and teacher at BavoEuropoort Psychiatric Institute, and the Municipal Health Centre of Rotterdam. He is involved in research projects concerning help seeking behaviour, emergency psychiatry, victimisation, assertive outreach, compliance, and coercion. He works as a psychiatrist in an ACT-team. He received more than thirty research grants and published over a hundred articles in (inter)national scientific journals and books.

A. Wierdsma, PhD sociologist and methodologist, is assistant-professor at Erasmus MC, Department of Psychiatry. His research is focused on public mental health care. Recent publications concern the potential of psychiatric case registers in public mental health studies, trends in the use compulsory admission, and conceptual and methodological issues in continuity of care research. 